\title{
Wealth, Health, and Inequality: Households Exposure to Environmental Hazards
}

\author{
Ebenezer Owusu-Sekyere, ${ }^{1}$ Elvis Attakora-Amaniampong, ${ }^{2}$ and Dacosta Aboagye ${ }^{3}$ \\ ${ }^{1}$ Department of Development Studies, University for Development Studies, Wa, Ghana \\ ${ }^{2}$ Department of Real Estate and Land Management, University for Development Studies, Wa, Ghana \\ ${ }^{3}$ Department of Geography and Rural Development, Kwame Nkrumah University of Science and Technology, Kumasi, Ghana
}

Correspondence should be addressed to Ebenezer Owusu-Sekyere; oseturbo@yahoo.com

Received 15 September 2015; Accepted 24 December 2015

Academic Editor: Siyue Li

Copyright (C) 2016 Ebenezer Owusu-Sekyere et al. This is an open access article distributed under the Creative Commons Attribution License, which permits unrestricted use, distribution, and reproduction in any medium, provided the original work is properly cited.

\begin{abstract}
This study examined the geographies of ecological hazards in the "Garden City" of West Africa, Kumasi. The data collection involved questionnaire survey of 300 households using proportional representative sample of residential communities. This was complemented with 6 focus group discussions and 12 in-depth interviews with officers involved in environmental management. The results show that the disparities in household exposure to environmental hazards were not only skewed towards the economically deprived communities but were also disproportionately biased against the indigenous communities. The research views this development as an indication of poor urban environmental management and confirms how lack of holistic environmental planning has led to injustice in the exposure to environmental hazards. We argue that a proper environmental management framework has to be developed to correct the inequalities in order to guarantee social cohesion within the entire urban space.
\end{abstract}

\section{Introduction}

Rapid urbanization, rising income inequality, and increasing class segregation have produced a geographic concentration of affluence and poverty throughout the world, creating a radical change in the geographic basis of human society [1]. Generally, as the magnitude of poverty and social inequality rises in the environment of the poor, so is their exposure to health hazards resulting from unhygienic environments [2]. Worldwide, cities in developing countries including Ghana are regarded as carrying a disproportionate burden of household environmental hazards and diseases, with approximately 35 percent of the disease burden in Africa being attributed to environmental factors [3].

The Kumasi Metropolis, like cities in most developing nations, is characterised by intensified poverty, informality, and inequality resulting from the increasing and unprecedented population growth rates. With a population of about 487,504 in 1984 , the city's population is hovering around $2,200,919$ with an annual growth rate of 5.4 per cent [4], which is one of the highest recorded in the subregion [5] but this has not been accompanied by investments in environmental services [6]. About one-third of the population lives in underserved communities where households are economically deprived and socially constrained [7]. Unless authorities prepare the city to meet some of their environmental challenges, the social consequences could be detrimental.

The city is still at the first stage of the urban environmental transition where most common environmental problems occur at the household and neighbourhood levels; the disposal of domestic waste faces problems related to storage, collection, transportation and final disposal [8]. Most human excrement and household wastes end up in streams, drains, gullies and ditches untreated. Water supply is threatened both in quality and in quantity [9]. These unsafe conditions contribute to serious health problems, in addition to compromising the aesthetic quality of the city. There is a sharp contrast between affluence and poverty and this tends to manifest itself in the segregation of social groups within different residential communities [10].

In Ghana research on the effect of urbanization in relation to the environment have concentrated on comparisons 
between urban-rural differentials and have mainly ignored intra-urban details. For this reason, the plight of the urban poor has become a fairly invisible theme on the local authorities' developmental agenda. Indeed, few studies have examined how inadequate provision of urban environmental management infrastructure has led to unsanitary environments and how such practices threaten the health of the entire society $[11,12]$. Such studies also tend to focus on specific issues as housing, health, overcrowding and basic services, trying to identify specific links or trends, rather than examining how health threats are distributed over the entire urban space in the first place.

In this study, we examine how urban environmental hazards are constructed and amplified using the urban environmental transition model put forward by [12], and who within the urban space are most at risk using [13]. Specifically, it focuses on the inequalities in exposure to household environmental hazards among the different socio-ecological groups and its impact on health. The study argues that although Kumasi may statistically have had its fair share of development, the massive urbanization may have resulted in the overconcentration of environmental hazards in specific locations [14].

Although environmental threats to human health are numerous, this research concentrates on traditional hazards which are related to poverty and insufficient development including lack of access to safe drinking water, indoor air pollution from cooking and heating using coal or biomass fuel, and inadequate solid waste disposal [15]. We acknowledge that while the kinds of environmental hazards households in the KMA face may not differ from cities in other developing countries; their severity, incidence, and socioeconomic bases may be radically different. Building a knowledge and awareness base on this matter is therefore important. The research contributes to this endeavor by providing empirical data on the Kumasi situation. After these introductory remarks, the paper proceeds with the conceptual framework guiding the study. The subsequent section discusses the research approach and the context of the study area. The empirical results and the analysis of the study are given much prominence after the methodological approach. The concluding part highlights the fact that there are real social disparities in household exposure to environmental problems in the KMA and therefore policy intervention for the marginalized ought to be stepped up.

\section{Environment, Wealth, and Health Nexus: Literature Perspective}

The link between social inequality and health has been well established in literature [16-18]. While these scholars argued that every facets of the environment ultimately exert some influence on human health and well-being, it is the intimate environment of their home and neighbourhood which exerts the greatest and most immediate influence on people's wellbeing [19]. Bartlett [18] argues that while the link between environment and societal well-being is often conceptualized in terms of health, the environmental impact on well-being goes beyond human health to include access to quality of housing and community spaces, emotional and self-esteem, and security.

The urban environmental transition model which guides this study postulates that the nature of environmental problems and, for that matter, sanitation challenges in cities have an inverse relationship with levels of economic development. The model argues that, in cities of low income countries, health risks related to the environment are more located in the immediate environs of homes, neighbourhoods, and workplaces. These challenges include problems of waste disposal (both solid and liquid) indoor and outdoor air pollution, inadequate or contaminated water supply, poor and overcrowded housing, smoky kitchens, insect infestation, contaminated food, and poor drainage among others [20, 21]. The model argues that the reverse is the case in countries that have moved into the middle and high income category. In these countries, environmental hazards that pose risk to health reduce in importance, and the emergence of city-wide challenges such as ambient air pollution and river pollution predominates [19]. This is because, at an advanced stage of development (high-income status), cities in these countries are able to address both neighbourhood/home and citywide environmental changes. Although cities in the wealthy nations use far more resources, they are also able to use part of the wealth to avoid personal exposure to unpleasant and hazardous pollutants at both the neighbourhood/home and city-wide levels [20, 22].

It can be argued that the framework provides better perspectives for understanding the sanitation challenges in cities in the developing world. This is because the model describes a linear development path and the sanitation characteristics of low, middle, and high-income cities and how these wealth classes are disproportionally affected by poor environmental sanitation, a case that the illustrates the importance of wealth as perpetuating classism.

\section{Methodology}

3.1. Study Area. Kumasi is located in the transitional forest zone and is about $270 \mathrm{~km}$ north of the national capital, Accra [7]. The unique centrality of the city as a traversing point from all parts of Ghana makes it a special place for many to migrate. The high rate of population growth has outstripped the rate of infrastructure development and service provision. Most of the facilities have exceeded their carrying capacities.

The housing environment in some parts of Kumasi is illsuited for human habitation because they are characterised by poor drainage and sanitation. Staggeringly, the majority of the housing facilities (almost 60 percent) do not have toilet facilities and, therefore, open defecation is a common place [5]. In some cases, house owners have turned in-house toilets into rooms and rented them out to people. This presents a further challenge to the Metropolitan Assembly's long term goal of reducing dependence on public toilets in favour of household facility usage [5].

3.2. Data Collection. Data collection involved multiple techniques which were built into a three-stage research design. 
TABLE 1: Selection of sample population.

\begin{tabular}{lcc}
\hline Study locality & Number of houses & Quota \\
\hline Asewase Zongo & 2525 & 150 \\
Asafo $^{* *}$ & 587 & 100 \\
Ahodwo $^{* * *}$ & 270 & 50 \\
Total & 3382 & 300 \\
\hline
\end{tabular}

Extracted from KMA 2010 ( ${ }^{*}$ Low Class Residential; ${ }^{* *}$ Medium Class Residential Communities; ${ }^{* * *}$ High Class Residential Communities).

The first stage was a survey of 300 households, using a representative sample of residential areas stratified by residential categories derived from the five year Medium Term Development Plan of the Kumasi Municipal Assembly, see Table 1. This stratification distinguishes residential areas of the city principally based on the common characteristics such as the type of houses, access to sewage, type of waste collection service, and access to sanitation facilities. Three distinguishing housing strata were identified: High Class Residential Communities (HCRC), Medium Class Residential Communities (MCRC), and Low Class Residential Communities (LCRC).

The HCRC comprises single-family high income housing, blocks of flats, privately built estates, and government-built high income estates. These communities have in-house toilet facilities and waste disposal system independent of public toilets and public or communal waste disposal sites. The MCRC include the multistorey compound houses and private middle income housing. This sector usually has toilet facilities in the house and is sometimes served by either house-tohouse waste collection service or communal waste disposal sites. It has well laid-out drains (gutters) on streets. The LCRC includes the traditional houses such as compound houses and slums. These are usually single-storey with rectangular courtyard or are made up of wooden structures. They are usually served by communal waste disposal sites, public toilets, and very often lack concrete drains or sewage. Within each residential category, one locality was purposively selected as follows: Ahodwo represents HCRC, Asafo represents MCRC, and Asawase Zongo represents LCRC.

These localities were chosen because they had a perfect characteristics of the residential categorisation described above. A quota value was then apportioned to each study locality, see Table 1. Since Asewase Zongo had the highest number of housing units, it had the highest share of the quota value, followed by Asafo and Ahodwo in that order. It is from each housing unit that the head of the household was selected for the survey. In each household, efforts were made to interview a woman since the cultural arrangements of the study localities were such that household environmental issues were mostly the responsibility of the women. They were therefore in a better position to give accurate answers.

The issues covered in the survey included the socioeconomic profile of households; access to and use of basic services such as housing, water, sanitation, and energy; and health indicators, namely, malaria, diarrhoea, and acute respiratory infections using a three month symptoms recall procedure. The following symptoms were used: malaria: fever and increase in body temperature; diarrhoea: passing loose watery stool more than three times in a day and vomiting; acute respiratory infections: dry cough, wet cough, and runny nose.

The second stage of the design involved a more qualitative study where six focus group discussions (FGD) were conducted among individuals and groups drawn from the various residential localities. The inclusion criteria for the focus groups were based on the social profile of respondents which was representative of the community and access to basic environmental services. Two sets of focus group discussions were conducted in each of the residential classifications. The first sets of the discussions were held for men while the second was held for women. This dichotomy was necessary so as to allow each group to express their views independently of gender roles in the home. Each group consisted of at least five (5) discussants. The FGD was conducted by research assistants who were familiar with the terrain and who could speak and interpret the local dialect very eloquently. Each FGD lasted for about 45 minutes. The issues discussed included the knowledge, attitudes, and perceptions of households/individuals about the household environment, health, and the need for improvement. This approach is deemed appropriate when the object of the research is to explore reactions of a group or community in response to some commonly experienced aspects of their environment [5]. Through such interactive discourses, participants were able to offer insights on the perspective of the community, revealing clues to the social contexts that shape their opinions [23].

The third stage of the design involved detailed interviews with twelve officials from the Waste Management Department of the Kumasi Metropolitan Assembly, the Metropolitan Environmental Health Unit, the Metropolitan Health Administration, the Community Water and Sanitation Agency, Ghana Water Company Limited, and Community Health Nurses. The interviews were conducted by the researchers themselves. These interviews were carried out to identify the constraints to policy implementation and service delivery. These methods were supplemented with personal observations. Particular attention was paid to the environments in and around homes, work places, and markets.

3.3. Data Analysis. After careful editing, the quantitative data obtained from the household survey was entered into Statistical Package for Social Sciences (SPSS for Windows) for analysis. Chi-square $\left(\chi^{2}\right)$ was used to measure the relationship between household wealth and exposure to environmentally related problems. Significance was determined by a probability value of less than or equal to $0.05(p<0.05)$. The qualitative data from the focus group discussions and interviews were analyzed using large content analysis.

\section{Results and Discussions}

4.1. Indoor Pollution. The main source of indoor pollution came from the types of cooking and heating fuel available to the various households. A significant share of households in the low income communities depended heavily on use of solid fuels such as wood and charcoal. The results indicate that wood fuel was the principal cooking fuel for $79.2 \%$ 


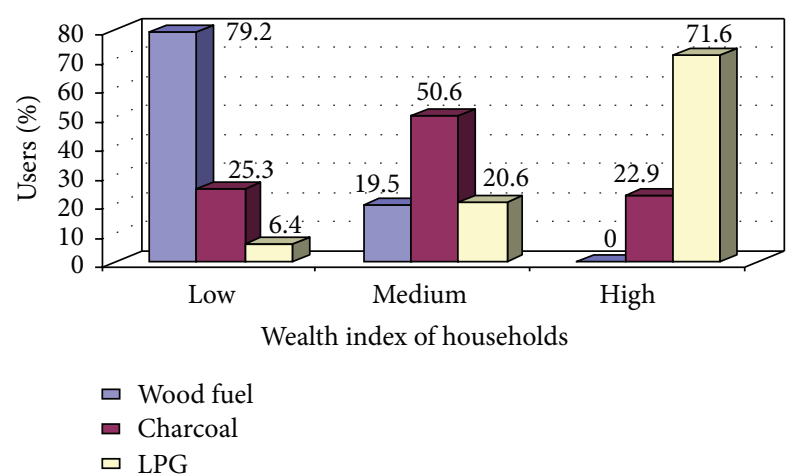

FIgURE 1: Primary fuel used for cooking according to wealth (\%).

low wealth households followed by charcoal (19.5\%). About $51 \%$ of the medium wealth households had charcoal as their principal cooking fuel with $25.3 \%$ using wood fuel for cooking. For $71.4 \%$ of the wealthy households, liquefied petroleum gas (LPG) was the principal cooking fuel, but charcoal usage was also prevalent (Figure 1). A chi-square analysis showed a significant relationship between household wealth and the principal cooking fuel ( $p=0.001$ at 95 percent confidence interval).

Additionally, households using LPG supplemented it with charcoal as a way of providing security in cases of LPG supply shortages, which is a regular phenomenon in the metropolis. Interestingly, respondents from the wealthy homes still preferred stirring "Banku and Rice Balls" two popular local dishes on charcoal stoves because the respondents claim it preserved the traditional flavour of the food than to prepare it on LPG stoves. No matter how weird this may sound, such perception exists among many "rich" people in Ghana, a situation that confirms the popularity of charcoal. The study further revealed that the use of solid fuels was common to all wealth groups because of cost and low risk, as against the perceived high risk associated with LPGs. For this reason some households, whether rich or poor did not allow their children and house helps to use LPG for fear of fire explosion, a common cause of residential fires in the metropolis. Undoubtedly, solid fuel as a heating and cooking methodology is not limited to the KMA but common in Ghanaian cities, as media reports indicate that, annually, over 13 million tonnes of wood is processed into charcoal [24].

Solid fuels emit substantial amounts of pollutants, including respirable particles, carbon monoxide, nitrogen and sulphur oxides, and benzene [21] which can have profound health impact on the principal home maker. Besides, much of the traditional cooking in Ghana requires fairly constant attention and vigorous stirring while heating, which often means the cook has to bend over the pot and sometimes immersed themselves in the smoke from the fire. The continuous exposure to the fumes from the cooking fuel could have dire health consequences on the principal home maker. Figure 2 indicates the association between households' sources of solid fuel and the prevalence of Acute Respiratory Infections (ARI).

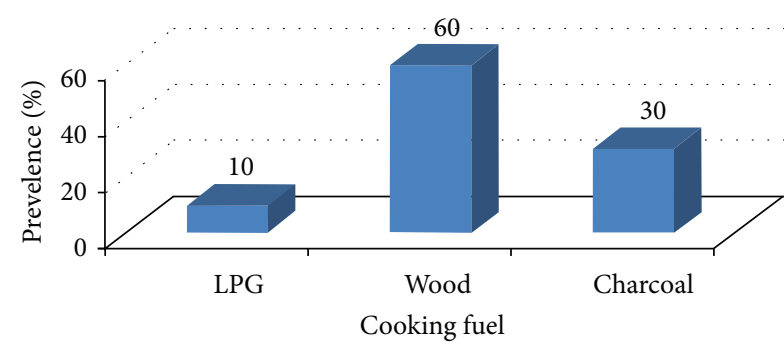

FIGURE 2: Relationship between cooking fuel and respiratory problems.

TABLE 2: Reported frequency of mosquito bites by household wealth.

\begin{tabular}{lccc}
\hline \multirow{2}{*}{ Wealth index } & \multicolumn{3}{c}{ How frequently do you experience mosquito bites? } \\
& Not at all & Few times & Many times \\
\hline Low & $0 \%$ & $10 \%$ & $90 \%$ \\
Medium & $0 \%$ & $15 \%$ & $85 \%$ \\
High & $0 \%$ & $25 \%$ & $75 \%$ \\
\hline
\end{tabular}

Whereas ARI was common to all households, users of wood and charcoal fuels reported higher percentage of ARI than users of LPG, (see Figure 2). The research further showed that the preference for charcoal by consumers also related to cost. One woman explained in the focus group discussion that she pays 50 GHS ( $\$ 30$ at February, 2014 exchange rate) to refill a $14 \mathrm{~kg}$ of LPG which could last for barely two weeks but pays $9.00 \mathrm{GHS}$ (\$3) for a sack of charcoal every one month. This cost is exclusive of the inconvenience of having to carry the empty cylinder around to get it filled. The reason for the popularity charcoal is obviously the direct capital costs of using LPG.

These findings confirm postulates by $[25,26]$ that cooking with solid fuel accounts for the largest share of indoor air pollution in many developing countries [26]. Solid fuel use was associated with nearly 2 million deaths in 1990, and over 1.2 million of these deaths were attributed to acute respiratory infections (ARI) in children [21]. Solid fuel use accounts for around 4.9 per cent of deaths and 4.4 per cent of Disability Adjusted Life Years (DALYs) in developing countries.

4.2. Exposure to Mosquitoes. The research further revealed that while mosquito bite was common to all households, respondents in the low income communities reported higher frequency of mosquito bite than their counterpart in the medium and high wealth communities (Table 2).

The high responses from the poor homes were due to the insanitary conditions in and around their immediate environment and the fact they did not have the ability to afford control measures. The frequency of mosquito biting maintained a significant relationship with household wealth $(p=$ 0.001 at 95 percent confidence interval). The researchers' own experience was not different from the views expressed. There were many occasions where the researchers and their assistants had to wear long clothes or smear themselves with insect repellents before they could continue with the data collection. 


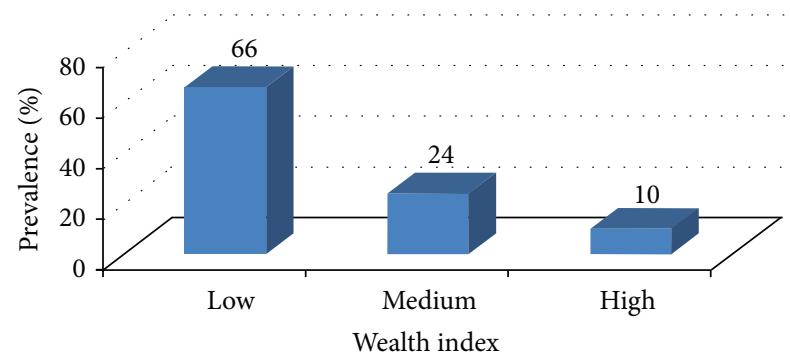

FIGURE 3: Relationship between wealth and malaria (\%).

The presence of mosquitoes in domestic environments is widely recognised by $\mathrm{WHO}$ as a potential health hazard in urban areas because of their ability to carry disease pathogens [27]. They also cause a lot of discomfort and annoyance by their bites and buzzing sounds. Again, their bites, stings, and contact can cause unpleasant reactions. Poor silage disposal and blocked drains facilitate mosquito breeding [27]. It was therefore not surprising that mosquitoes were found far more frequently in the low income neighbourhoods characterised by choked drains and rampant dumping of waste in open spaces.

The link between mosquito bites and the incidence of malaria was obvious as respondents who reported high frequency of mosquito bites also reported repeated occurrence of malaria. Malaria cases were identified using the symptoms of fever. Since the major manifestation of malaria is fever, accompanied by increase in body temperature, respondents were asked whether they or any of their children had fever in the month preceding the survey. The research revealed that malaria was common among all the residential classes but was higher among households in the low income communities than their counterparts in the medium and high income neighbourhoods. As shown in Figure 3, about 66\% of the households in the low income communities reported experiencing repeated cases of fever presumed to be malaria compared to their counterparts the medium and high income neighbourhoods.

Generally, the frequency of mosquito bite cannot be used as an indicator for the occurrence of malaria because there was no clinical testing for the presence of the malaria parasite in respondents. However, the purpose is to appreciate the likely coincidence between the incidence of malaria and mosquito bite. This will hopefully, arouse interest for a more detailed follow-up research into the subject matter. Since mosquitoes are implicated in a whole host of unpleasant diseases such as malaria, yellow fever, filarial, brain fever, and dengue [28], it can be used to support the results displayed in Figure 3. To further support the link between frequency of mosquito bite and incidence of malaria, a focus group discussion (FGD) was organized for some community members. A 35-year-old seamstress gave her description of the situation during the community discussions when she intimated that

hardly will a week pass by without taking a family member to the hospital because of malaria. We are aware the high incidence of malaria is because of the frequent mosquito bite that we experience but what can we do. May be, the city authorities may have to intensify the spraying they do or else, all of us will die out of malaria,

she concluded subtly. As a follow-up to her concerns, one of our key informants (a doctor at Manhyia Hospital at Asewase) explained in an interview that

the number of malaria cases we attend to have increased almost four fold, am sure this might be due to the high population and poor environmental conditions in the communities. You know at first, this was not the case but since the massive development of slums, the sanitation has deteriorated and cases of malaria and other environmental diseases have increased. Something must be done or else the situation may explode one day.

When asked what could be the cause of the reoccurrence of the malaria cases, the doctor blamed it on the high frequency of mosquito bites originating from the insanitary conditions.

4.3. Exposure to Flies. The presence of flies in the home was related to sanitation facilities available to the household. Generally, the research revealed that access to better waste management facilities within the metropolitan area was skewed against the low income and indigenous communities. Whereas households in the high and middle income communities had a better system of managing waste and this attracted a minimal number of flies, households in the low income communities used public dumping sites that were located in the heart of the neighbourhood. The insanitary conditions provided safe haven for flies and other insects. Ironically, attempts by the city authorities to deal with the solid waste menace have resulted in the adoption of management solutions which further worsens the plight of the poor contributing to health risks and water pollution $[29,30]$.

The study revealed that households in the low income communities reported having more flies in homes (91.7\%) than households in the high income neighbourhoods (8.3\%). The presence of flies was a source of worry to respondents as indicated by the responses from the focus group discussions,

The situation is worse after public holidays and festive occasions. You may think the flies in the whole metropolis have been sent here, similar to that of mosquitoes,

a fifty-four-year-old man at Asewase Zongo. Similar sentiments were expressed by a food vendor in the community,

Now nobody wants to buy from here because they say as you eat, you must drive away the flies with your left hand which creates a lot of inconvenience. In addition, the flies may enter your food and could make you sick.

The presence of flies presented a risk of exposure to food and drinks. Our study revealed that respondents who reported having many flies in the home also reported higher prevalence of childhood diarrhoea. Coincidentally, households 
TABLE 3: Frequency of cockroaches in homes by household wealth.

\begin{tabular}{lccc}
\hline \multirow{2}{*}{ Wealth index } & & \multicolumn{2}{c}{ How frequently do you see cockroaches in your homes? } \\
& Not at all & Few times & Many times \\
\hline Low & $0 \%$ & $4 \%$ & $96 \%$ \\
Medium & $0 \%$ & $22 \%$ & $78 \%$ \\
High & $0 \%$ & $28 \%$ & $72 \%$ \\
\hline
\end{tabular}

who reported having more flies were those in the low income neighbourhoods. This by implication means that households in the low income neighbourhoods suffered more from diarrhoea than their counterparts in the high income neighbourhoods. It is however important to recognise the fact that the presence of flies by itself may not directly be a cause of diarrhoea but flies are seen here as major carriers of the diarrhoea pathogen.

Generally, insanitary toilets facilities at homes were associated with having more flies in the home area. Respondents who had Pit and Pan Latrines in their homes reported the highest presence of flies followed by KVIP (KVIP (Kumasi Ventilated Improve Pit) is a type of toilet facility common in Ghana) latrines. The use of these two types of toilet facilities was common in the low income communities. These facilities also come with their own set of challenges [31]. Prominent among these was how to properly dislodge the content. Due to the limited number of treatment sites (if there are any at all), septage from the facilities is disposed of either in water bodies or in nearby drains and open spaces, where the disadvantaged are located [32]. On many occasions, the usage of these facilities was a source of conflicts among households since they are shared facilities and, therefore, their maintenance was done in turns depending on the household on duty. The use of in-house flush toilet (water closets) did not seem to attract flies. In-house flush toilet facilities were common in the high income homes and, within a house, the researchers could count more than three of such facilities allocated to individuals. The exposure to flies as a risk hazard was thus minimal. Flies constitute health hazards as well as annoyance. As they feed and breed on manure and garbage, these insects are likely to pick up disease-causing organisms. Such flies contaminate human food by crawling on the surface and depositing dark spots as well as regurgitating liquid [27]. Flies have been implicated in the spread of over 30 bacterial and protozoan diseases such as typhoid fever, tuberculosis, dysentery, polio, anthrax, diarrhoea, yaws, cholera, conjunctivitis, trachoma, tapeworm, hookworm, and pinworm [27, 33]. Fortunately, house flies do not transmit many of these diseases with great frequency.

4.4. Exposure to Cockroaches. In this study, the presence of cockroaches in the house was associated with the same environmental conditions as flies. Consequently, over $96 \%$ of the households in the low income homes reported frequently seeing cockroaches in the house. The households in the high and medium income homes reported the lowest presence of cockroaches in the house (Table 3 ).

Table 3 shows that the presence of cockroaches was common to all residential communities irrespective of
TABLE 4: Households access to water supply by wealth (\%).

\begin{tabular}{lccc}
\hline \multirow{2}{*}{ Source of water supply } & \multicolumn{3}{c}{ Wealth index of households } \\
& Low & Medium & High \\
\hline In-house piping & 5.0 & 10.2 & 59.7 \\
Public standpipe & 26.5 & 34.9 & 20.6 \\
Borehole/well & 42.5 & 37.3 & 7.9 \\
Stream & 19.1 & 12.1 & 4.8 \\
Rain water & 5.9 & 2.0 & 1.0 \\
Vendor & 3.0 & 2.5 & 6.0 \\
Total & 100.0 & 100.0 & 100.0 \\
\hline
\end{tabular}

their socioeconomic status, though the poorer households reported the most. Cockroaches have been implicated in the transmission of human diseases. They have been implicated to harbour the yellow fever virus and bacterial agents of cholera, pneumonia, and diphtheria among others [26]. It is therefore important that they are always kept away from human habitation.

4.5. Household Source of Water Supply. In Kumasi, water supply is undertaken by the Ghana Water Company Limited (GWCL) from two treatment stations, the Barekese and Owabi treatment stations, but many of the residents supplement their limited supply with water from streams/rivers and wells due to limited and erratic supplies. Indeed, whereas the quantity of available water is decreasing, the quality is also being compromised mainly due to high population growth accompanied by low investments by the state. The study revealed that one factor the influence access to water was wealth. Table 4 demonstrates the link between household wealth and access to water supply.

Our research revealed that over $80.3 \%(59.7+20.6)$ of respondents in the high income homes depended on pipe borne water supplied by the GWCL. On the contrary, respondents in the low income households relied on boreholes and streams $61.6 \%(42.5+19.1)$ as their sources of water. Water from the streams and boreholes was not normally pretreated by the end-point users and was therefore predisposed to series of water borne infections including diarrhoea. It therefore came without surprise, when the research revealed that the prevalence of diarrhoea reached the peak in the major rainy season when the water sources became heavily contaminated due to excessive flooding. Households who mostly supplement their limited water supply with water from streams and boreholes also reported high cases of 


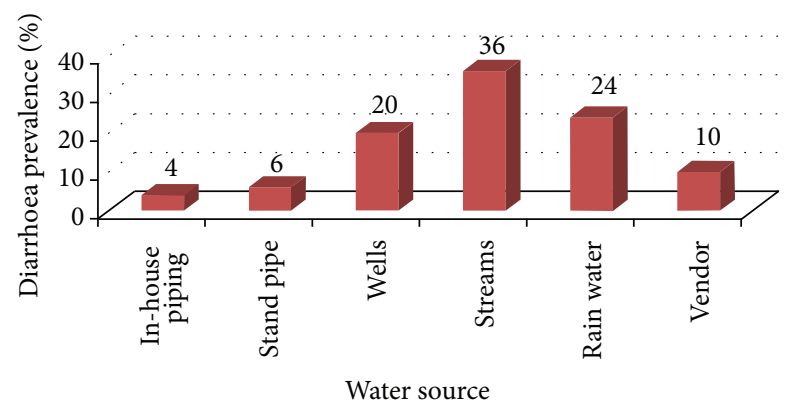

Figure 4: Household sources of water and diarrhoea (\%).

TABLE 5: Practice of water storage by wealth (\%).

\begin{tabular}{lccc}
\hline \multirow{2}{*}{ Container used } & \multicolumn{3}{c}{ Wealth index of households } \\
& Low & Medium & High \\
\hline Overhead tank & 0 & 4.8 & 57.1 \\
Barrel & 18.8 & 51.8 & 23.8 \\
Pot & 61.7 & 13.3 & 4.8 \\
Plastic container & 14.3 & 30.1 & 14.3 \\
Bucket & 5.2 & 0 & 0 \\
Total & 100.0 & 100.0 & 100.0 \\
\hline
\end{tabular}

diarrhoea than households who depended on water from pipe borne water (Figure 4).

It is important to state that the results, which only pertain to the period of fieldwork from May to October, 2014, a period of severe rainfall and water pollution in the study area, should be interpreted with caution. The risk of contamination of streams and rain water was due to the poor environmental conditions in the neighbourhood. Apart from water from streams, users of water from wells and vendors also significantly reported higher incidence diarrhoea. This may be due to the possibility of transmitting pathogenic organisms from the insanitary environments during the period of heavy rainfall to these water sources.

Another source of water contamination was due to water storage strategies adopted by the households to cope with irregular and disruptions in water supply. Household water storage strategies provided reservoirs for disease pathogens and other insects. Table 5 shows the water storage strategies by the various wealth groups. Here, respondents were asked to mention just one most important water storage container. The most common water storage container was the pot, 36.4 percent, followed by the barrel, 29 percent, and the plastic container, 18.6 percent. Only 13.3 percent of households used overhead tanks to store water. The research shows that whereas the wealthy could afford the use of overhead tanks which was safer and hygienic, the poorer households had to depend on pot, barrel, and plastic containers. These are less safe and hygienic means of storing water. Even though the use of overhead tanks did not prevent parasitic worms or bacteria in the water, it was relatively far safer than other less expensive containers. Whilst most pots and barrels did not have covers, they were also kept outdoors, mostly due to a lack of space

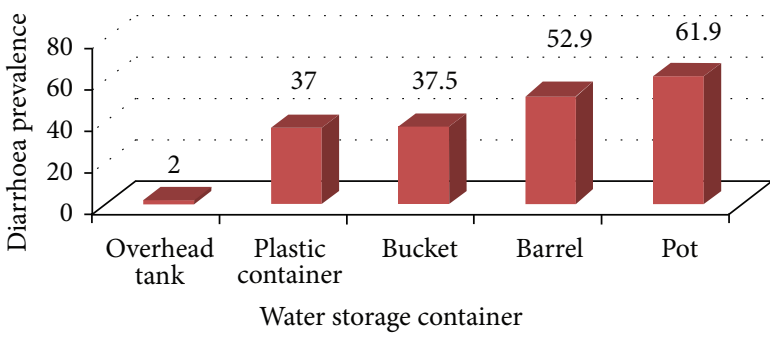

Figure 5: Relationship between water storage container and diarrhoea (\%).

indoors. This situation further aggravated the extent of water pollution.

The water storage strategy adopted also had implications on the health of the household. As indicated in Figure 5, households who stored water in pots and barrels and other less safe containers reported higher frequencies diarrhoea occurrences, suggesting a high rate of in-house water contamination. The use of pots to store water in particular appeared to be related to a household's ethnicity. Traditionally, the pot has been the most popular container for storing water in the KMA. This probably was due to the absence of other storage containers in the area in some time past, bearing in mind Kumasi's status as the largest cultural city in West Africa and the fourth in the world [34]. Even with the abundance of more hygienic means of storing water, such as the overhead tanks and plastic containers, most poor households prefer to store their water in pots.

Of particular importance to health considerations was the way the pots and their contents were treated. Generally, the pots were placed in the interior courtyards of compound houses, usually not covered and exposed to dust and domestic animals. In addition, these pots were hardly disinfected, since most households did not know about disinfection. Children within the compound usually scooped water directly from the pots, with any "reasonably" clean cup or bowl for drinking, thus increasing the risk of contamination.

The high prevalence of diarrhoea diseases in Kumasi suggests a major underlying water safety problem. While most water borne diseases are sporadic and often not reported, water borne disease outbreaks may take on massive proportions. The pollution of the rivers leads to the breeding of vectors which transmit varied water related diseases such as malaria, typhoid, cholera, amoebic dysentery, and diarrhoea. Children are mostly vulnerable to water related diseases because they play regularly in the polluted rivers and this involves direct body contact and ingestion when swimming in the rivers.

\section{Conclusion}

This study has demonstrated clearly that there are discernable spatial patterns of exposure to environmental health problems within metropolitan Kumasi, with the majority of the low income communities disproportionately disadvantaged. Using a selective set of indicators, this study 
has assessed how households in low income communities in the KMA are exposed to a number of environmental problems and their contribution to the burden of diseases. These environmental risk factors contributed in no small way to the high prevalence of malaria, diarrhoea, and respiratory diseases in the metropolis. Evidence from the above analysis suggests that major determinants of health outcomes lie within the household environment. The observed differences in the incidence of diseases among different social groups show how poor urban environmental management and wealth which are rhetorically interrogated have contributed in perpetuating intraurban environmental health inequalities in metropolitan Kumasi.

Each component of the environment is clearly an important risk factor in itself. However, when located within the context of the household environment, the complexities involved with characterising the health effects of interrelated risk factors become apparent. In addition to this, the ease of infection transmission between members of a household and other households is related, inter alia, to the degree of interdependence on and interaction with other people in the neighbourhoods. There is no gainsaying that environmental quality is an important direct and indirect determinant of human health. Deteriorating environmental conditions are a major contributory factor to poor health and poor quality of life and hindrance to sustainable development. Addressing household environmental problems, therefore, needs coordinated and intersectoral approaches. The responsibility for addressing these issues rests with the individual home owner, the local authorities, and the national government. The main premise of this study is that successfully and effectively addressing the vulnerabilities and risks to which the low income populations are increasingly being exposed may, perhaps, require complete rethinking of current urban development trajectories if sustainable transitions are to be achieved.

\section{Conflict of Interests}

The authors declare no conflict of interests.

\section{Authors' Contribution}

Ebenezer Owusu-Sekyere and Elvis Attakora-Amaniampong conceived the idea and did the preliminary write-up; Dacosta Aboagye performed the analyses; Ebenezer Owusu-Sekyere, Elvis Attakora-Amaniampong, and Dacosta Aboagye jointly drafted and edited the paper. All authors read and approved the final paper.

\section{Acknowledgments}

The authors wish to thank all the study participants, the staff of the Kumasi Metropolitan Assembly, and the Metropolitan Health Directorate for their immense help.

\section{References}

[1] D. Massey, For Space, Sage, London, UK, 2005.
[2] J. E. M. Arguello, R. Grant, M. Oteng-Ababio, and B. M. Ayele, "Downgrading - an overlooked reality in African cities: reflections from an indigenous neighborhood of Accra, Ghana," Applied Geography, vol. 36, pp. 23-30, 2013.

[3] M. Oteng-Ababio, "Rethinking waste as a resource: insights from a low-income community in Accra, Ghana," City, Territory and Architecture, vol. 1, article 10, 2014.

[4] Kumasi Metropolitan Assembly Waste Management Department (KMA), Statistics of Waste Management in Kumasi and Bantama, Statistical Data, Kumasi Metropolitan Assembly, Kumasi, Ghana, 2012.

[5] Ghana Statistical Service (GSS), Ghana Population and Housing Census, Ghana Statistical Service, Accra, Ghana, 2010.

[6] D. Awunyo-Vitor, S. Ishak, and G. S. Jasaw, "Urban households' willingness to pay for improved solid waste disposal services in Kumasi Metropolis, Ghana," Urban Studies Research, vol. 2013, Article ID 659425, 8 pages, 2013.

[7] KMA (Kumasi Metropolitan Assembly), Data for Purposes of Planning Waste Management Intervention Programmes, Kumasi, Ghana, 2010.

[8] M. Oteng-Ababio, "Unscripted (in)justice: exposure to ecological hazards in metropolitan Accra," Environment and Planning A, vol. 45, no. 5, pp. 1199-1218, 2013.

[9] E. Owusu-Sekyere, "Scavenging for wealth or death? Exploring the health risk associated with waste scavenging in Kumasi, Ghana," Ghana Journal of Geography, vol. 6, pp. 63-80, 2014.

[10] G. Razzu, "Urban redevelopment, cultural heritage, poverty and redistribution: the case of Old Accra and Adawso House," Habitat International, vol. 29, no. 3, pp. 399-419, 2005.

[11] K. O. Boadi and M. Kuitunen, "Childhood diarrheal morbidity in the Accra Metropolitan Area, Ghana: socio-economic, Environmental and behavioral risk determinants," Journal of Health \& Population in Developing Countries, 2005, http://www.jhpdc .unc.edu/2005.

[12] J. Songsore, J. S. Nabila, Y. Yangyuoru et al., State of Environmental Health Report of the Greater Accra Metropolitan Area, Ghana Universities Press, Accra, Ghana, 2001.

[13] D. Satterthwaite, “The under-estimation and misrepresentation of urban poverty in IIED 1995, urban poverty: characteristics, causes and consequences," Environment and Urbanization, vol. 7, no. 1, p. 52, 1995.

[14] M. Martuzzi, F. Mitis, and F. Forastiere, "Inequalities, inequities, environmental justice in waste management and health," European Journal of Public Health, vol. 20, no. 1, pp. 21-26, 2010.

[15] World Bank, "Health and environment," Environment Strategy Paper No 1, Washington, DC, USA, 2001.

[16] J. Songsore and G. McGranahan, "Environment, wealth and health: towards an analysis of intra-urban differentials within the Greater Accra Metropolitan Area, Ghana," Environment \& Urbanization, vol. 5, no. 2, pp. 10-34, 1993.

[17] World Health Organization, The World Health Report 1996: Fighting Disease, Fostering Development, World Health Organization, Geneva, Switzerland, 1996.

[18] S. Bartlett, "Children's experience of the physical environment in poor urban settlements and the implications for policy, planning and practice," Environment and Urbanization, vol. 11, no. 2, pp. 63-73, 1999.

[19] G. Owusu, "Social effects of poor sanitation and waste management on poor urban communities: a neighborhood-specific study of Sabon Zongo, Accra," Journal of Urbanism, vol. 3, no. 2, pp. 145-160, 2010. 
[20] J. Songsore, Urbanization and Health in Africa: Exploring the Interconnections between Poverty, Inequality and the Burden of Disease, Ghana Universities Press, Accra, Ghana, 2004.

[21] L. Smith and L. Haddad, "Explaining child malnutrition in developing countries," IFPRI Research Report 11, IFPRI, Washington, DC, USA, 1999.

[22] G. McGranahan and J. Songsore, "Wealth, health and urban household: weighing environmental burdens in Accra, Jakarta and Sao Paulo," Environment, vol. 36, no. 6, pp. 40-45, 1994.

[23] J. A. Saleh, Assessment of a Pilot Franchised Solid Waste Collection Scheme in Kumasi, Kwame Nkrumah University of Science and Technology, Kumasi, Ghana, 2002.

[24] http://www.ghanamma.com/.

[25] K. L. Dionisio, S. Howie, K. M. Fornace, O. Chimah, R. A. Adegbola, and M. Ezzati, "Measuring the exposure of infants and children to indoor air pollution from biomass fuels in the Gambia," Indoor Air, vol. 18, no. 4, pp. 317-327, 2008.

[26] WHO, The World Health Report 2002: Reducing Risks, Promoting Health Life, World Health Organization, Geneva, Switzerland, 2002.

[27] WHO, Global Water Supply and Sanitation Assessment 2000 Report, World Health Organisation, Geneva, Switzerland, 2008.

[28] R. Kelly, The Demise of Small Mosquito Control Programs, vol. 22, Wing Beats, Atlanta, Ga, USA, 2011.

[29] N. Obirih-Opareh and J. Post, "Quality assessment of public and private modes of solid waste collection in Accra, Ghana," Habitat International, vol. 26, no. 1, pp. 95-112, 2002.

[30] M. Oteng-Ababio, "Beyond technical details: the stalled Kwabenya Engineered Sanitary Landfill Project in Accra, Ghana," Danish Journal of Geography, vol. 111, no. 2, pp. 169-179, 2011.

[31] G. A. Tipple, D. Korboe, G. Garrod, and K. Willis, "Housing supply in Ghana: a study of Accra, Kumasi and Berekum," Progress in Planning, vol. 51, no. 4, pp. 255-324, 1999.

[32] M. Oteng-Ababio, "The role of the informal sector in solid waste management in the Gama, Ghana: challenges and opportunities," Tijdschrift voor Economische en Sociale Geografie, vol. 103, no. 4, pp. 412-425, 2012.

[33] UN-HABITAT, State of African Cities 2008: A Framework for Addressing Urban Challenges in Africa, UN-HABITAT, Nairobi, Kenya, 2008.

[34] K. K. Adarkwa, "The changing face of Ghanaian towns," African Review of Economics and Finance, vol. 4, no. 1, 2012. 


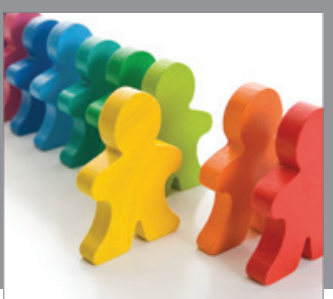

Autism

Research and Treatment
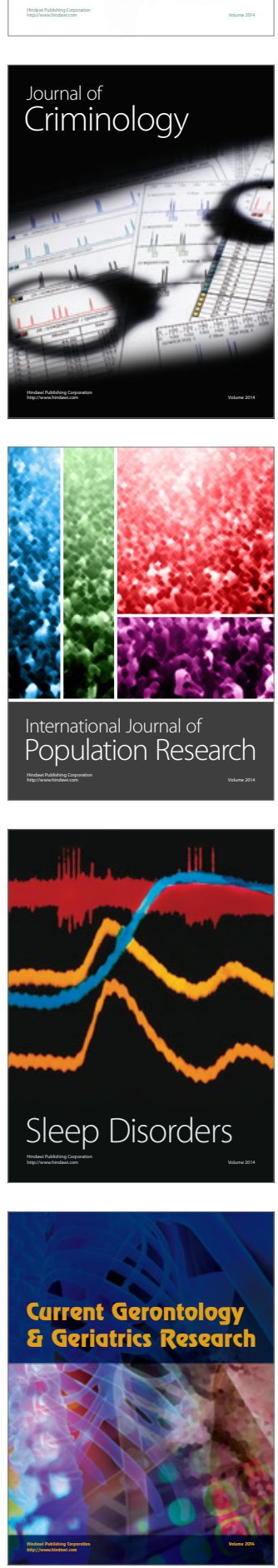

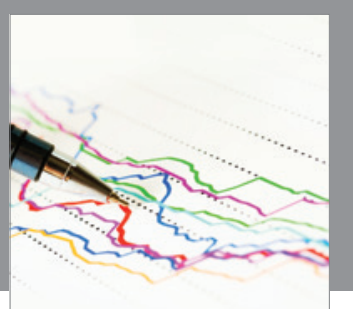

Economics

Research International
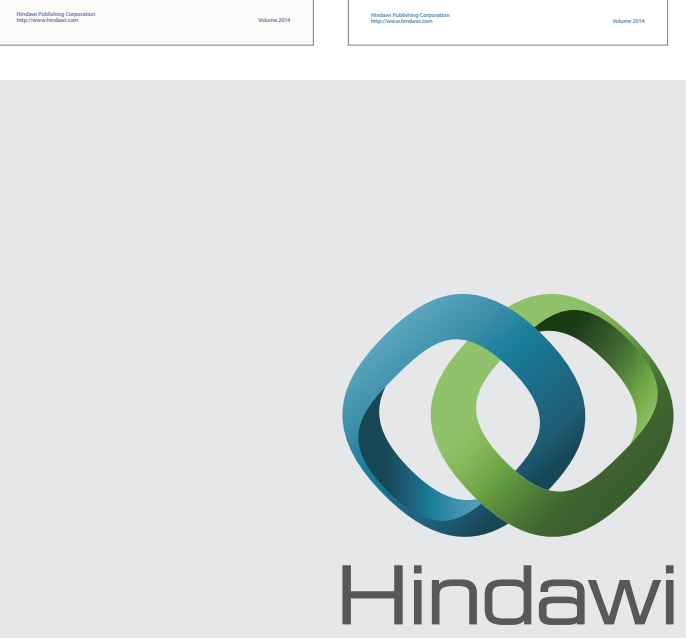

Submit your manuscripts at

http://www.hindawi.com
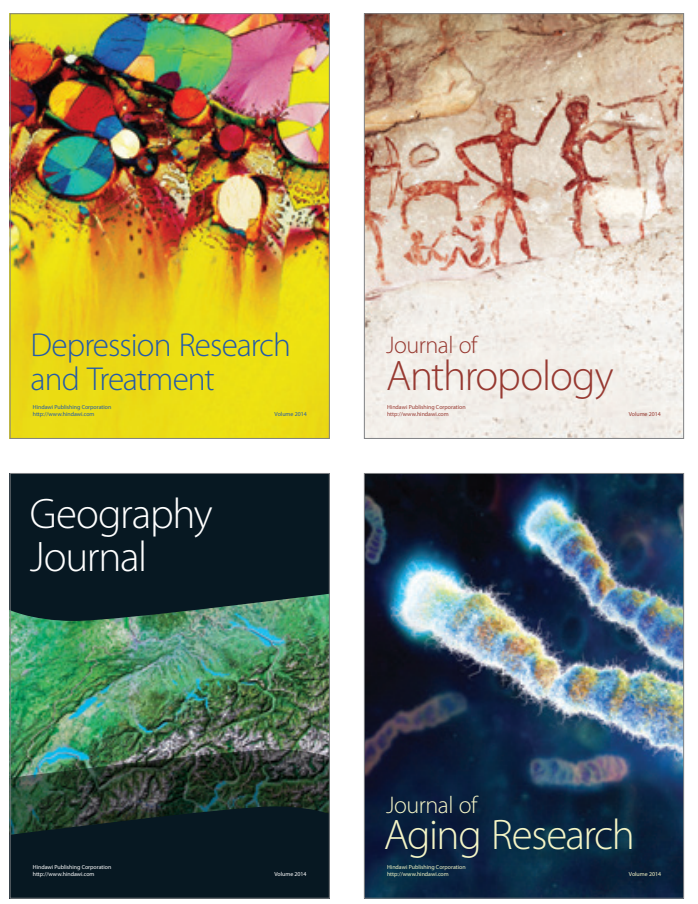
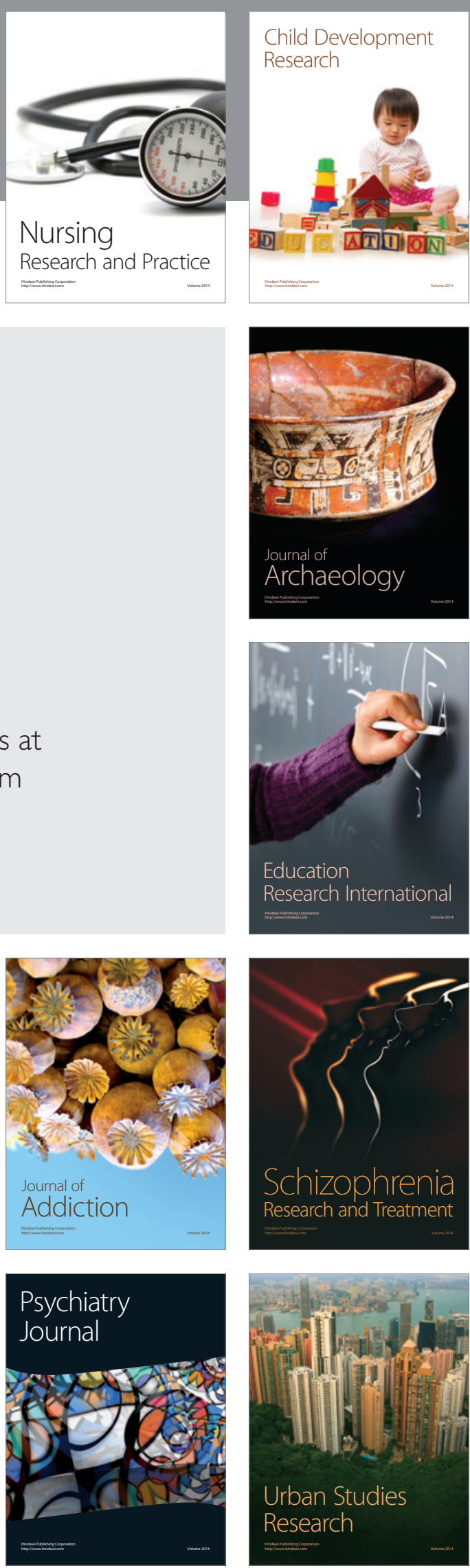